\title{
Tomada de decisão de compra de DVDs de filmes piratas: estudo com aplicação de regressão logística
}

\author{
Vanderli Correia Prieto ${ }^{\mathrm{a} *}$, Guilherme Migliavaca ${ }^{\mathrm{b} * *}$ \\ anniversidade Federal do ABC, São Bernardo do Campo, SP, Brasil \\ bUniversidade Presbiteriana Mackenzie, São Paulo, SP, Brasil \\ *vanderli.prieto@ufabc.edu.br, ***guilherme.migliavaca@gmail.com
}

\begin{abstract}
Resumo
0 Brasil é o quarto país onde mais se comercializam produtos piratas, com prejuízo à indústria, à economia e às relações internacionais. A despeito da importância deste assunto, há poucas evidências empíricas sobre a maneira como o consumidor decide se engajar na pirataria. Esta pesquisa se propõe a investigar se as variáveis compostas pelos aspectos comportamentais, econômicos, legais e éticos são relevantes para a tomada de decisão do consumidor em piratear ou não DVDs de filmes. A abordagem metodológica adotada foi quantitativa com o emprego da técnica de regressão logística binária. Os dados foram coletados junto a 205 estudantes de graduação. Os resultados da pesquisa sugerem que as variáveis de caráter legal e econômico tiveram maior peso na tomada de decisão do consumidor. Os resultados também demonstraram que fatores tais como considerar a pirataria ilegal, o preço do DVD original justo e ter informações sobre as consequências da pirataria diminuem a intenção de piratear.
\end{abstract}

Palavras-chave

Tomada de decisão. Consumidor. Comportamento. Regressão logística.

\section{Introdução}

A abrangência do que é considerado como pirataria ampliou-se ao longo do tempo. Antes, restringia-se apenas ao confisco e à revenda da propriedade privada e hoje, após a grande disseminação da internet, o conceito passou a englobar também a propriedade intelectual e a sua veiculação.

A pirataria é descrita como o ato de fazer ou distribuir cópias de produtos protegidos pelos direitos autorais e sem a autorização do autor, produtor e coautor, com exceção de uma cópia para o uso do próprio adquirente do produto legal (Gupta et al., 2004).

No Brasil, observa-se que, durante os últimos anos, o consumo de produtos piratas vem aumentando. Segundo dados da Câmara de Comércio Internacional, o país é o quarto onde mais se comercializam produtos piratas (Weinberg, 2007). Pesquisa publicada pela Federação do Comércio do Estado do Rio de Janeiro (2010) revela que, em 2006, 42\% dos entrevistados compraram algum produto pirata, em 2010 esse percentual aumentou para 48\%. Hoje, no Brasil, são aproximadamente 70,2 milhões de consumidores de mercadorias falsificadas. Nesse mesmo período aumentou significativamente o consumo de DVD pirata. Em 2006, o percentual de brasileiros que afirmou ter comprado DVD ilegal foi de 35\%. Em 2010, 77\% dos entrevistados assumiram ter adquirido um DVD pirata.

A pirataria também causa prejuízos à economia brasileira. Conforme a Associação Brasileira de Combate à Falsificação (ABCF), as estimativas apontam que 0 Brasil perdeu US\$ 20 bilhões com pirataria no ano de 2010 em impostos não arrecadados e prejuízos para as empresas (Landim \& Rehder, 2010).

As relações internacionais também são impactadas pela pirataria. Apenas em 2011 o Brasil foi excluído pelos Estados Unidos de sua lista de "mercados notórios", que aponta locais físicos e na internet, notórios pela venda de contrabando e produtos piratas. Esses locais são considerados como desafiadores pela Representação dos Estados Unidos para o Comércio - USTR (Marin, 2011).

A pirataria é um assunto frequentemente debatido no âmbito das indústrias, do comércio, da economia 
e das relações internacionais. No entanto, tem recebido pouca atenção da academia. Uma pesquisa pelos temas "pirataria" ou "falsificação" no site da Associação Nacional de Pós-Graduação e Pesquisa em Administração (2011), em eventos, publicações e revistas, retorna com apenas 8 artigos publicados.

Nesse cenário, o consumidor, além de decidir entre marcas e produtos similares, também delibera sobre comprar um produto original ou um pirata ou, ainda, se ele próprio pode pirateá-lo. No entanto, Coyle et al. (2009) afirmam que há poucas evidências empíricas sobre a maneira como o consumidor decide se engajar na pirataria.

Nesse contexto, o objetivo desta pesquisa é investigar a pirataria a partir do comportamento do consumidor. Trata-se de um campo de estudo que vem se expandindo e pode ser conceituado como as atividades diretamente envolvidas na aquisição, no consumo e na disposição de produtos e serviços, incluindo o processo de decisão que precede e determina essas ações (Engel et al., 2005).

0 estudo delimita-se ao consumo de DVDs piratas de filme ou o seu download não autorizado pela internet.

A pesquisa segue o modelo de tomada de decisão do consumidor adaptado de Coyle et al. (2009), que investigaram esta mesma relação quanto à pirataria de CDs no mercado de músicas nos Estados Unidos da América (EUA). Ao adotar esse modelo, esta pesquisa se propõe a investigar se as variáveis compostas pelos aspectos comportamentais, econômicos, legais e éticos são relevantes para a tomada de decisão do consumidor em piratear ou não DVDs de filmes.

0 estudo aplica o método quantitativo e utiliza a técnica de regressão logística binária para análise dos dados.

0 referencial teórico traça um breve panorama da pirataria no setor audiovisual e discute o comportamento do consumidor de produtos piratas do ponto de vista das variáveis que se propõe a investigar.

\section{Referencial teórico}

\subsection{Panorama brasileiro da pirataria no setor audiovisual}

0 Brasil é o $9^{\circ}$ maior mercado cinematográfico do mundo, apresentando um significativo potencial de crescimento (Brasil, 2009). Isso fica evidente quando se observa, por exemplo, que as, aproximadamente, 2.300 salas de cinema do Brasil correspondem a pouco mais da metade do total existente no México.

De acordo com os dados da Associação Antipirataria de Cinema e Música (2011), no setor audiovisual, o mercado brasileiro lançou, em 2006, cerca de 1,7 mil títulos de filmes em DVD e obteve um faturamento de mais de $\mathrm{R} \$ 700$ milhões em bilheteria de cinema. Ainda assim, o mercado perde com a pirataria, porque 59\% dos DVDs comercializados não são originais. Ainda segundo a APCM (Associação Antipirataria de Cinema e Música, 2011), as perdas mundiais com pirataria, para os estúdios de cinema, são de US\$ 6,1 bilhões, sendo que desse total os estúdios deixam de ganhar, na América Latina, o valor de US\$ 1 bilhão, o que representa $16,9 \%$ do total do prejuizo mundial. A cópia de filmes piratas (39\%) e o download pela internet (38\%) representam fontes de perda da indústria.

Relatório da Fecomércio RJ (Federação do Comércio do Estado do Rio de Janeiro, 2010) aponta que o binômio que sustenta a expansão da pirataria de DVDs é a agilidade com que hoje os falsificadores podem reproduzir essas mídias, em razão do avanço e disseminação da tecnologia, e o aumento significativo na venda de aparelhos de DVD. Estimativa da Fecomércio RJ (Federação do Comércio do Estado do Rio de Janeiro, 2010), com base em dados da Associação Nacional de Fabricantes de Produtos Eletroeletrônicos, indica que, de 2006 a 2010, foram vendidos, anualmente, em média, 7,2 milhões destes equipamentos no Brasil.

Segundo números da União Brasileira de Vídeo (2009), a indústria de vídeos vendeu aproximadamente 2 milhões de unidades a menos para os seus distribuidores no primeiro trimestre de 2008 , se comparado ao mesmo período de 2007. Esta queda pode ser explicada pelo fato de as locadoras terem reduzido seus pedidos em 600 mil filmes, enquanto o varejo em geral diminuiu as compras em 1,5 milhão de unidades.

No Brasil, desde 2004 foi criado o Conselho Nacional Contra à Pirataria (2009), instituição responsável pela aplicação de abordagens e metodologias para o combate à pirataria no país.

A pirataria na internet é combatida por meio de um departamento específico da APCM que faz o monitoramento de sites que oferecem conteúdo sem proteção à propriedade intelectual.

\subsection{Comportamento do consumidor no processo de aquisição de produtos piratas}

Conforme disposto por Mowen \& Minor (2006), há três perspectivas de pesquisa no campo do comportamento do consumidor: a da tomada de decisão, a experimental e a da influência comportamental.

Na primeira, foco desta pesquisa, os consumidores são percebidos como tomadores de decisões racionais e a compra é resultado da percepção do consumidor de 
que existe um problema, que pode ser uma necessidade ou um desejo, e do posterior processo racional de resolução do problema composto por várias etapas.

Vários fatores influenciam a tomada de decisão nesse processo. Neste trabalho a proposta é investigar a influência dos fatores econômicos, legais, éticos e comportamentais na compra ou aquisição dos produtos piratas, por isso a revisão bibliográfica se concentra nessas variáveis.

\subsubsection{Aspectos comportamentais}

Segundo Coyle et al. (2009), existem alguns indicadores que nos levam ao entendimento do comportamento do consumidor de produtos piratas, tais como: a pirataria como uma forma de avaliação e difusão, a tendência de exercer uma atividade particular de consumo, as diferenças individuais e a facilidade de se engajar em uma atividade de consumo.

0 processo de difusão ajuda a explicar como novas ideias ou práticas culturais, assim como novos produtos, são difundidas em uma sociedade. Lida com a maneira como um novo produto é adotado por uma sociedade (Engel et al., 2005).

No mundo de hoje, as tecnologias de informação como a internet e telefones celulares, que combinam aspectos dos meios de comunicação e os canais interpessoais, representam importantes instrumentos de difusão (Morris \& Ogan, 1996).

Um outro indicador é a tendência do consumidor exercer uma atividade particular de consumo, pois, segundo Dijksterhuis et al. (2008), os indivíduos têm a tendência de repetir comportamentos passados. As atitudes dos consumidores que já compraram ou consumiram um determinado produto tornam mais suscetíveis de prever os seus comportamentos de compra futura do que os daqueles que não têm tais experiências (Engel et al., 2005). Nesse sentido, os indivíduos que já praticaram pirataria no passado e tiveram resultados positivos com essa prática estão mais propensos a repeti-la.

As diferenças individuais, tais como as definidas pelas variáveis demográficas de gênero, idade e renda familiar, ajudam a definir o perfil da pessoa que consome ou pratica a pirataria. Estudos sugerem que os homens são mais propensos a consumir produtos que envolvam a tecnologia. Por outro lado, as mulheres costumam ter uma postura mais ética do que os homens em suas decisões (Ruegger \& King, 1992). Pessoas de mais idade tendem a possuir uma postura mais conservadora do que os jovens, quando os assuntos envolvem moral e ética (Ruegger \&King, 1992). A renda familiar também é outra importante variável demográfica relevante no comportamento do consumidor e está negativamente relacionada com a pirataria (Solomon, 2002).

\subsubsection{Aspectos econômicos}

Segundo Coyle et al. (2009), a percepção do consumidor quanto às perdas econômicas advindas da pirataria pode influenciar a sua decisão de consumo. Nesse sentido, alguns consumidores podem decidir não piratear caso considerem o impacto econômico para os produtores.

0 comportamento do consumidor também é influenciado pela possibilidade de não se sentir beneficiado com a compra de um produto original. Caso o consumidor não consiga perceber uma relação equilibrada entre o que será investido em uma compra e a utilização do produto que será adquirido, o mesmo poderá não realizar essa compra. Se for de extrema necessidade, a tendência é o consumidor buscar substitutos, até mesmo a sua versão pirata (Coyle et al., 2009).

No caso de filmes, a indústria introduziu novas tecnologias para reprodução, que exigem adequação e introduzem custos muitas vezes indesejados pelos consumidores (Harmon, 2003).

0 mercado de filmes piratas permite ao consumidor comparar o preço de aquisição da versão original com a versão pirata. A pirataria pode vir a ser considerada pelo consumidor como uma resposta a um modelo de mercado já estabelecido, principalmente no tocante aos preços praticados (Coyle et al., 2009).

No Brasil, o relatório publicado pela Fecomércio RJ (Federação do Comércio do Estado do Rio de Janeiro, 2010) aponta que nenhum dos malefícios e prejuízos do consumo ilegal é levado consideravelmente em conta na hora da compra de produtos piratas, sendo o preço baixo o fator decisivo. Segundo o relatório, em 2010 94\% dos que consumiram produtos piratas afirmaram que o custo mais baixo é o que os atrai. Em 2006, o percentual era praticamente o mesmo: 93\%.

\subsubsection{Aspectos éticos}

No momento da compra, o consumidor é influenciado pela hierarquia de seus valores (Engel et al., 2005), e, por esse motivo, o consumo de produtos piratas pode até mesmo assumir valores mais importantes em detrimento da ética e do aspecto legal, por exemplo, se for considerado como meio de enriquecimento cultural (Liang, 2004). Ainda segundo o autor, a pirataria tem uma ética própria de resistência contra o monopólio dos direitos do autor que vai além do simples ganho material, sendo também a única forma de enriquecimento cultural de populações economicamente desfavorecidas.

Segundo Mowen \& Minor (2006), o consumidor é altamente influenciado pela sociedade onde vive 
e não necessariamente discerne entre o certo e o errado, ético e antiético, ou seja, mesmo que um indivíduo identifique que o download é uma forma antiética de consumo, ele poderá fazê-lo, caso isso seja aceitável naquela sociedade.

A percepção do certo ou errado é de consciência do praticante e do consumidor da pirataria, e o mesmo sabe que a prática é antiética, mas busca no anonimato, na liberdade gerada pela internet e no formato tecnológico conveniente a desculpa para a prática e para o consumo (Freestone \& Mitchell, 2004).

\subsubsection{Aspectos legais}

As considerações legais, segundo Naím (2006), abrangem não só a legislação nacional e a internacional como também a atuação dos governos e entidades públicas na repressão e prevenção da pirataria; as punições, sanções e o conhecimento pela população das leis e do conceito de pirataria e de propriedade intelectual.

No que tange à legislação brasileira, encontram-se as seguintes leis que tratam do assunto: Lei $n^{\circ}$ 9.609/98 (Propriedade Intelectual de Programas de Computador) (Brasil, 1998b); Lei n 9.610/98 (Direitos Autorais) (Brasil, 1998a); e o Decreto-lei 2.848/40 (Código Penal) (Brasil, 1940). As duas primeiras referem-se às ações cíveis cabíveis, que objetivam a reparação do dano causado pelo ato ilícito praticado, e a última é relacionada às ações penais, que exercem o papel de prevenção geral e especial, com o objetivo de evitar futuras lesões através da imposição de pena ao autor do crime. Para o Código Penal (artigo 184, Brasil, 1940), responde pelo crime de pirataria quem distribui, vende, adquire, oculta ou tem em depósito cópia de obra intelectual ou fonograma sem autorização dos autores.

Segundo Coyle et al. (2009), a ignorância dos consumidores a respeito das leis de direitos autorais e a complexidade destas podem ser consideradas como algumas das responsáveis pela aquisição de produtos piratas. Ainda nesse estudo, os autores apontam que, apesar de saberem que a pirataria é algo errado e que é um crime que gera punições, os consumidores continuam adotando práticas ilícitas por estarem seguros de que não serão identificados nem punidos.

Gundlach \& Murphy (1993) apontam que as leis, por refletirem uma sociedade, estão intimamente ligadas com o embasamento ético dos consumidores. Contudo, perante a pirataria, os estados possuem um desafio de conscientizar e mostrar à população que baixar um filme, uma série pela internet ou que comprar um DVD pirata é um crime tão grave quanto o assalto a uma loja, pois em ambos ocorrem uma violação.
Vários autores tratam da dificuldade da conscientização da pirataria como crime, tais como Brasil (2009), Cox et al. (1990) e Nettler (1984). Para Brasil (2009), a percepção da violação aos direitos autorais como um crime é dificultada por se tratar de uma propriedade intelectual e imaterial. Além disso, a internet permitiu o acesso a conteúdos sem autorização do autor com maior facilidade e frequência, gerando a denominada Pirataria Digital (Gandelman, 2001).

Segundo análise de Albers-Miller (1999), os consumidores fazem uma relação de contrabalancear os aspectos financeiros, éticos e legais quando adquirem um produto pirata, e que o alto preço dos DVDs e softwares é um fator que intensifica esse consumo, já que a sensação de satisfação de seus interesses econômicos ao comprar um produto pirata barato ou até de graça, quando baixados da internet, compensa o fato de este consumo não ser ético nem legal.

Nesse sentido, Gupta et al. (2004) fizeram uma análise demonstrando que os aspectos legais e éticos deveriam ser combinados pelos consumidores como um indicador na variável atitude de consumo ilegal. No mesmo artigo, os autores mostram a discussão sobre se os aspectos legais devem ser estudados juntos ou separados dos aspectos sociais, pois a pirataria pode ser considerada tolerável se, apesar de não ser eticamente prescrita, é desejável por um grupo social e pela comunidade tecnológica. Com os resultados de suas pesquisas, porém, chegam à conclusão de que estas variáveis devem ser estudadas separadamente, conforme já defendido por Bommer et al. (1987). lsso porque analisaram que o aspecto legal possui relação tanto com os aspectos sociais quanto éticos, mas, na mente do consumidor, o aspecto ético tem uma conexão mais forte com o legal do que o social apresenta.

Para um combate eficaz à pirataria, demanda-se uma atuação dos governos, porém poderá levar à vivência do dilema apresentado por Gupta et al. (2004) de que, apesar de ser ilegal, a pirataria de DVDs e softwares gera efeitos benéficos ao facilitar a difusão da cultura e do conhecimento, devido ao preço menor, e isto pode até gerar crescimento econômico para o país, e o seu combate reduzirá estes benefícios.

Os estudos de Coyle et al. (2009) demonstram que a prática de consumir ou fazer o download de produtos piratas envolve uma análise da questão ética e comportamental de uma maneira mais profunda e que a questão econômico-financeira vem agravando a pirataria, porém o aspecto legal também deve ser considerado, visto que, enquanto os consumidores tiverem a percepção de que não serão identificados e punidos, esta prática tende a ser seguida. 
Nesse sentido, autores como Chang (1998) e Gupta et al. (2004) apontam soluções no sentido de se investir na educação e conscientização dos consumidores.

\section{Procedimentos metodológicos}

Conforme exposto na seção introdutória, o objetivo deste estudo é verificar a influência dos fatores éticos, econômicos, comportamentais e legais na intenção do consumidor em piratear DVDs de filmes.

Para esta pesquisa foram coletados dados primários. 0 instrumento de coleta de dados proposto por Coyle et al. (2009) com o intuito de investigar a pirataria entre os consumidores de música foi adaptado para o contexto deste trabalho: a pirataria de DVDs de filmes.

Os dados foram coletados utilizando-se uma amostra não probabilística, composta por 205 estudantes de graduação de cursos de Administração de Empresas, Ciências Contábeis e Economia de uma das maiores universidades particulares da cidade de São Paulo.

Inicialmente o questionário foi elaborado com 21 questões. Após o pré-teste realizado com 20 estudantes, efetuaram-se modificações na redação de sete assertivas e a eliminação de uma questão. 0 questionário final (Apêndice A) ficou com 20 questões organizadas como segue: na primeira parte são captados dados referentes ao perfil do respondente, variáveis SEXO e RENDA.

$\mathrm{Na}$ segunda parte mensuram-se aspectos referentes à variável comportamental, sendo: frequência que assiste filmes (FREQassist), fonte que utiliza (FONTutil), hábito de piratear ou não (HABlpir), frequência com que pirateia (FREQpir), tendência de continuar pirateando (TENDpir), motivo para não piratear (MOTIVnPir).

$\mathrm{Na}$ terceira e quarta partes são mensurados aspectos legais e éticos referentes à comercialização, às leis e ao download como forma de pirataria, sendo compostas pelas seguintes variáveis: punição para quem comercializa (PUNIcom), punição para a pessoa que pirateia (PUNIpes), conhecimento das leis brasileiras (CONHleis), pirataria como prática ilegal (PIRileg), reconhecimento de downloads como forma de pirataria (DOWNpir), facilidade de ser descoberto pelas autoridades (DESCaut), download de filmes prejudica alguém (DOWNprej) e pirataria ou download como forma de divulgação da cultura (DIVcult).

E em seguida são avaliados os aspectos econômicos que afetam a intenção de piratear, sendo: noção de preço de um DVD original (PRECdvd), o quanto produtos piratas afetam o lucro das produtoras (LUCRprod), se a pirataria contribui para o aumento no preço dos DVDs originais (AUMprecDVD) e se a economia de um país é afetada pela pirataria (PIRafetECON).

A variável dependente (INTpir), intenção de comprar ou não DVDs piratas, resultou da combinação de duas questões, sendo que na primeira o consumidor deveria responder sim ou não à pergunta: Você já comprou DVD pirata e/ou fez download de filmes? E na segunda o consumidor deveria assinalar uma alternativa (ex.: é barato, é de fácil acesso) para a pergunta: Você compraria DVD pirata ou faria download de filmes novamente, principalmente por quê? Foram considerados consumidores com a intenção de comprar DVDs piratas aqueles que combinaram a resposta "Sim" à primeira questão e também assinalaram alguma alternativa diferente de "Não compraria novamente" na segunda questão.

No tratamento preliminar dos dados, dos 205 questionários respondidos, 202 foram considerados válidos.

Os dados foram, então, analisados utilizando-se a estatística descritiva e a técnica de regressão logística binária. 0 software utilizado foi o SPSS (Statistical Package for Social Sciences), versão 18.0.

A regressão logística é uma técnica estatística de análise multivariada utilizada em situações em que a variável dependente é binária, assumindo valores iguais a 0 ou 1 (Hair et al., 2005). Essa técnica permite estimar a probabilidade que está associada à ocorrência de um determinado evento utilizando-se de um conjunto de variáveis independentes ou explicativas. No caso desta pesquisa, o modelo foi definido tendo como variável dependente a intenção de comprar ou não DVDs piratas e como variáveis independentes os aspectos comportamentais, legais e éticos da tomada de decisão do consumidor.

Os coeficientes estimados para as variáveis independentes são estimados usando-se o valor logit como medida dependente, expresso pela fórmula 1 (adaptada de Hair et al. (2005)):

$$
\text { Logit }_{i}=\ln \left[\frac{\text { prob }_{\text {evento }}}{1-\text { prob }_{\text {evento }}}\right]=b_{o}+b_{1} X_{1}+\ldots+b_{n} X_{n}
$$

\section{Apresentação e análise dos resultados}

Inicialmente, foi feita uma análise descritiva dos dados, permitindo conhecer o perfil dos participantes do estudo. Verificou-se que 54,5\% dos entrevistados são do sexo masculino e $45,5 \%$ do sexo feminino, sendo que, entre o primeiro grupo, 92,73\% responderam já ter comprado DVD pirata, e no segundo, 80,43\%, sendo no total da amostra $87,13 \%$ de respostas afirmativas. 
Quanto ao comportamento do consumidor em relação à pirataria, 48,51\% declararam ter comprado DVD pirata ou feito download mais de dez vezes no último ano (2009); 11,88\% entre 6 e 10 vezes; $18,32 \%$ entre 2 e 5 vezes; apenas 5,94\% uma vez e $2,48 \%$ nenhuma vez. 0 restante $(12,87 \%)$ respondeu não à questão: Você já comprou DVD pirata e/ou fez download de filmes?

A renda familiar de 53,47\% da amostra está acima de dez salários mínimos, mostrando o predomínio das classes média e alta. Mesmo com esta predominância (variável econômica), 78,71\% dos estudantes da amostra consideram o preço dos DVDs originais caros, $14,36 \%$ consideram o preço justo, apenas 1,98\% o percebem como barato e 4,95\% não souberam opinar.

Esta junção de alta renda dos respondentes e suas percepções de alto preço dos DVDs originais sugere que, ao contrário da afirmação de Solomon (2002), a renda familiar não foi um fator relevante na decisão de comprar DVD pirata e ela não diminui, necessariamente, a prática de pirataria.

Com relação à frequência com a qual assistem filmes, 61,39\% declararam que assistem filmes frequentemente, $17,82 \%$ raramente e $20,79 \%$ sempre o fazem. Nota-se ainda que não houve, dentre os questionários válidos, a resposta nunca assistem filmes, tornando a pesquisa sobre a compra de DVDs piratas ou download de filmes mais interessante por focar num público-alvo deste lazer.

Quanto à fonte dos filmes vistos, uma minoria opta pela compra de DVD original $(2,48 \%$ dos estudantes) enquanto 30,69\% preferem comprar DVD pirata ou baixar da internet, e o restante da amostra se distribui entre cinema $(19,80 \%)$, alugar DVD (21,29\%), TV (25,74\%).

\subsection{Ajuste do modelo}

0 modelo de regressão logística foi ajustado empregando-se o método forward stepwise, no qual as variáveis são adicionadas uma por vez no modelo. A primeira variável a ser incluída é a de maior correlação com a variável dependente, e assim sucessivamente. 0 processo termina quando a última variável incluída no modelo tem coeficiente de regressão insignificante ou todas as variáveis foram incluídas no modelo.

0 modelo final apresentou boa qualidade de ajuste, conforme pode ser observado pelas análises que se seguem.

A medida básica de quão bem o procedimento de estimação de máxima verossimilhança se ajusta é dada pelo valor de verossimilhança. 0 ajuste é medido com o valor -2 vezes o logaritmo do valor da verossimilhança, chamado de -2LL ou $-2 \log$ verossimilhança (Hair et al., 2005). 0 índice -2LL, no passo 1, era de 150,182 e foi reduzido para 89,122 no último passo, indicando, assim, melhor ajuste do modelo.

Neste sentido, a acuracidade do modelo também pode ser verificada por meio do $\mathrm{R}^{2}$ de Cox e Snell e do $R^{2}$ de Nagelkerke. A medida $R^{2}$ de Cox e Snell opera com valores maiores indicando maior ajuste do modelo. No entanto, está limitada no sentido de não poder alcançar o valor máximo de 1 . A medida de Nagelkerke inclui o domínio de 0 a 1. Essas duas medidas refletem a quantia de variação explicada pelo modelo logístico, com 1,0 indicando ajuste perfeito (Hair et al., 2005).

0 valor de $\mathrm{R}^{2}$ de Cox e Snell foi de 0,385 enquanto que o $\mathrm{R}^{2}$ de Nagelkerke apresentou o valor de 0,627. Portanto, o modelo final (passo 6) explica 62,7\% do comportamento da amostra, ou seja, o modelo explica $62,7 \%$ do comportamento do consumidor quanto à intenção de piratear.

Segundo Hair et al. (2005, p. 264), a medida final de ajuste do modelo é o valor de Hosmer e Lemeshow, o qual mede a correspondência entre valores reais e os previstos da variável dependente. Foi apurado um valor de Hosmer e Lemeshow de 3,169 com p-valor de 0,923 . Desta forma, não se deve rejeitar a hipótese nula de que os valores reais não diferem dos valores previstos, uma vez que o p-valor está acima 5\%.

0 modelo também pode ser avaliado quanto a sua qualidade de discriminação da amostra em grupos de compradores e não compradores de DVDs piratas, utilizando-se para tanto a análise da curva de sensibilidade e especificidade, denominada Receiver Operating Characteristic (ROC).

\subsection{Análise da significância das variáveis}

Efetuados os testes de validação do modelo de regressão logística, foram identificadas as variáveis relevantes presentes no modelo final. Os resultados dos coeficientes do modelo e seus respectivos níveis de significância estão apresentados na Tabela 1.

A significância das variáveis do modelo pode ser avaliada por meio do teste de Wald e o seu correspondente Valor-p - vide Tabela 1. Nesta análise foi adotado um nível de significância de 5\%. Assim, um valor-p abaixo de 5\% indica a rejeição da hipótese nula de que o coeficiente beta da variável em análise é igual a zero.

0 valor beta ( $\beta$ ) estima o impacto de cada variável na decisão do consumidor de piratear ou não DVD. Um coeficiente beta de valor maior indica que a variável favorece o evento da pirataria. 
Tabela 1. Análise da significância das variáveis do modelo.

\begin{tabular}{|c|c|c|c|c|c|c|}
\hline Variável & $\beta$ & S.E. & Wald & $\mathrm{df}$ & P-valor & $\operatorname{Exp}(\beta)$ \\
\hline SEXO & 1,314 &, 577 & 5,185 & 1 & ,023 & 3,719 \\
\hline PRECdvd & $-2,164$ &, 725 & 8,905 & 1 & ,003 & , 115 \\
\hline PUNlcom (não punir) & 3,433 & 1,251 & 7,524 & 1 & ,006 & 30,957 \\
\hline PUNpes & $-2,148$ &, 747 & 8,262 & 1 & ,004 &, 117 \\
\hline PIRileg & $-1,942$ &, 543 & 12,780 & 1 & ,000 & , 143 \\
\hline DIVcult & ,680 & ,302 & 5,075 & 1 &, 024 & 1,975 \\
\hline Constant & 8,384 & 2,608 & 10,334 & 1 & ,001 & 4377,510 \\
\hline
\end{tabular}

Fonte: Elaborado pelos autores (2013).

A coluna $\operatorname{Exp}(\beta)$ fornece uma estimativa do logaritmo natural (ln) do odds ratio (razão entre a chance de um evento ocorrer em um grupo sobre a chance de ocorrer em outro grupo) ajustado para as variáveis do modelo.

Interpretando o coeficiente $\beta 1$ da variável SEXO (sexo do respondente), encontramos o coeficiente estimado pelo modelo igual a 1,314. Aplicando o exponencial sobre este coeficiente obtemos o valor 3,719 , que representa uma estimativa ajustada do odds ratio para o sexo do respondente. Verifica-se que consumidores do sexo masculino aumentam a chance da tomada de decisão das pessoas de consumirem DVDs de filmes piratas. Trata-se de uma diferença individual de gênero que, segundo Ruegger \& King (1992), pode ser explicada pelo fato de que as mulheres são influenciadas a ter uma postura mais ética do que os homens em suas decisões.

Analisando-se a variável PRECdvd, verifica-se que quando os consumidores consideram o preço do DVD original justo, diminui a chance da tomada de decisão de piratear $(\exp (B)=0,115)$. Este dado confirma a influência da variável econômica, como mostrado pelas pesquisas da Fecomércio RJ (Federação do Comércio do Estado do Rio de Janeiro, 2010) e por Coyle et al. (2009). 0 fator preço tem sido para a maioria das pessoas um dos principais motivos para o consumo de produtos piratas, e se o consumidor não percebe a relação entre custo e benefício equilibrada na compra de produtos originais, ele opta pelos produtos piratas (Coyle et al., 2009).

Verifica-se, também, que consumidores favoráveis à impunidade para quem comercializa DVDs piratas (variável PUNIcom) fazem com que aumente a chance na tomada de decisão das pessoas a consumirem DVDs de filmes piratas $(\exp (B)=30,957)$. Nesse sentido, 0 fato de as pessoas, mesmo sabendo que a pirataria é ilegal, continuarem a praticá-la pode também ser explicado por não temerem a identificação pessoal de seus atos e a respectiva punição (Coyle et al., 2009).

Quanto à opinião dos respondentes sobre quem compra DVD pirata e/ou faz download de filmes, consumidores que estão de acordo que devem ser informados de todas as consequências (PUNpes) apresentaram um $\exp (\mathrm{B})$ de 0,117 reduzindo, portanto, a chance na tomada de decisão das pessoas a consumirem DVDs de filmes piratas.

Consumidores que concordam que a pirataria de filmes é uma prática ilegal (PIRileg) diminuem a probabilidade de decidir pela pirataria de DVDs (exp(B) de 0,143), enquanto que consumidores que concordam que a prática da pirataria ajuda a levar cultura a quem consome (DIVcult) aumentam a probabilidade do consumo de DVDs de filmes piratas (exp(B) de 1,975). Desta forma, se nota mais uma vez a influência do aspecto legal nesta tomada de decisão, visto que, como mencionado por langenderfer \& Cook (2001), a ignorância do que é proibido e permitido sobre a pirataria e download de filmes é um agravante desta prática e, por isso, ações educativas e de fiscalização auxiliariam a disseminação das leis e conscientizariam a população. É interessante ressaltar que essa percepção de ilegalidade deve ser real e visível para não favorecer a pirataria, pois, como citado nos estudos de Cox et al. (1990), as pessoas não têm a mesma noção de crime para uma ação de roubar um DVD numa loja e para comprar um DVD pirata, recaindo menor culpa sobre a pirataria.

\section{Considerações finais}

Esta pesquisa se propôs a investigar se as variáveis compostas pelos aspectos comportamentais, econômicos, legais e éticos são relevantes para a tomada de decisão do consumidor em piratear ou não DVDs de filmes.

A intenção de comprar ou não DVDs piratas, variável dependente do estudo, considerou como tendo a intenção de fazê-lo os consumidores que já compraram DVD pirata e/ou fizeram download de filmes e têm a intenção de repetir o comportamento.

A pesquisa sugere que as variáveis de caráter legal e econômico tiveram maior peso na tomada de decisão do consumidor, corroborando resultados da pesquisa divulgada pela Fecomércio RJ (Federação do Comércio do Estado do Rio de Janeiro, 2010). Segundo essa pesquisa, entre 2006 e 2010 os consumidores 
apresentavam pelo menos um produto falsificado que não comprariam, enquanto em 2010 13\% dos entrevistados disseram que não teriam resistência a nenhuma mercadoria pirata.

Para as pessoas que nunca compraram DVD pirata nem fizeram download de filmes, os principais motivos desta escolha foram: a má qualidade de imagem e som (50\%), ideia de prejuízo aos profissionais da área $(7,69 \%)$ e visão de ser uma conduta antiética $(42,31 \%)$. A variável ética influencia mais a decisão de não comprar que a legal, sendo que nenhum entrevistado respondeu que não o fez por medo de ser punido legalmente.

0 modelo de regressão logística mostrou-se eficiente para determinar a probabilidade de ocorrência dos valores preditos da variável dependente. Com base nos resultados, o modelo conseguiu explicar $62,7 \%$ do comportamento dos consumidores quanto à intenção de comprar ou não DVDs piratas.

Não é objetivo desta pesquisa indicar ações para combater a pirataria, mas considerando-se que aspectos éticos não foram relevantes no modelo de decisão, corrobora-se afirmação de autores como Fecomércio RJ (Federação do Comércio do Estado do Rio de Janeiro, 2010) e Gundlach \& Murphy (1993) de que ações de combate à pirataria não devem ter apenas o foco na punição para quem comercializa, mas na educação do consumidor.

Este estudo apresenta a limitação de ter utilizado uma amostra não probabilística, gerando conclusões que não devem ser generalizadas. Um grupo específico e restrito da população brasileira está representado na amostra, composta por estudantes universitários das classes A e B. Sugere-se ampliar o estudo, incluindo as classes $C$ e $D$, que têm adquirido maior poder de consumo.

\section{Referências}

Albers-Miller, N. D. (1999). Consumer misbehavior: why people buy illicit goods. Journal of Business Ethics, 16(3), 273-287.

Associação Antipirataria de Cinema e Música. (2011). Pirataria audiovisual e fonográfica: estatísticas, aspectos técnicos e jurídicos. Recuperado em 24 de abril de 2011, de http:// www.apcm.org.br/estatisticas.php

Associação Nacional de Pós-Graduação e Pesquisa em Administração. (2011). Portal de eventos e publicações em revistas e congressos. Recuperado em 24 de abril de 2011, de http://www.anpad.com.br/busca_resultado.php

Bommer, M., Gratto, C., Gravander, J., \& Tuttle, M. (1987). A behavioral model of ethical and unethical decision making. Journal of Business Ethics, 6(4), 265-280. http://dx.doi. org/10.1007/BF00382936.

Brasil. (1940, dezembro 7). Código Penal (Decreto-Lei $n^{\circ} 2.848$, de 7 de Dezembro de 1940). Diário Oficial da República Federativa do Brasil. Recuperado em 13 de setembro de 2009, de http://www.planalto.gov.br
Brasil. (1998a, fevereiro 19). Altera, atualiza e consolida a legislação sobre direitos autorais e dá outras providências (Lei $n^{\circ}$ 9.610, de 19 de Fevereiro de 1998). Diário Oficial da República Federativa do Brasil. Recuperado em 13 de setembro de 2009, de http://www.planalto.gov.br

Brasil. (1998b, fevereiro 19). Dispõe sobre a proteção da propriedade intelectual de programa de computador, sua comercialização no País, e dá outras providências (Lei $n^{\circ}$ 9.609, de 19 de Fevereiro de 1998). Diário Oficial da República Federativa do Brasil. Recuperado em 13 de setembro de 2009, de http://www.planalto.gov.br

Brasil. Ministério da Justiça. (2009). Brasil original. Brasília. Recuperado em 1 de setembro de 2009, de http://www. mj.gov.br/services/.../FileDownload.EZTSvc.asp?

Chang, M. K. (1998). Predicting unethical behavior: a comparison of the theory of reasoned action on the theory of planned behavior. Journal of Business Ethics, 17(16), 1825-1834. http://dx.doi.org/10.1023/A:1005721401993.

Conselho Nacional de Combate à Pirataria. (2009). Estratégias de atuação. Recuperado em 7 de setembro de 2009, de http://portal.mj.gov.br/combatepirataria/data/Pages/ MJF3D9F395ITEMIDCD8BA37314944CFCB03096AB53A 89074PTBRIE.htm

Cox, D., Cox, A. D., \& Moschis, G. P. (1990). When consumer behavior goes bad: an investigation of adolescent shoplifting The Journal of Consumer Research, 17(2), 149-159. http:// dx.doi.org/10.1086/208545.

Coyle, J. R., Gould, S. J., Gupta, P., \& Gupta, R. (2009). To buy or to pirate: the matrix of music consumers' acquisitionmode decision-making. Journal of Business Research, 62(10), 1031-1037. http://dx.doi.org/10.1016/j.jbusres.2008.05.002.

Dijksterhuis, A., Preston, J., Wegner, D. M., \& Aarts, H. (2008). Effects of subliminal priming of self and God on selfattribution of authorship for events. Journal of Experimental Social Psychology, 44(1), 2-9. http://dx.doi.org/10.1016/j. jesp.2007.01.003.

Engel, J., Blackwell, R., \& Miniard, P. (2005). Comportamento do consumidor (8. ed.). Rio de Janeiro: LTC.

Federação do Comércio do Estado do Rio de Janeiro. (2010). Pirataria: radiografia do consumo. Recuperado em 24 de abril de 2011, de http://www.fecomercio-rj.org.br/publique/ media/estudo.pdf

Freestone, O., \& Mitchell, V. W. (2004). Generation Y attitudes towards e-ethics and internet-related misbehaviours. Journal of Business Ethics, 54(2), 121-128. http://dx.doi. org/10.1007/s10551-004-1571-0.

Gandelman, H. (2001). De Gutenberg à Internet: direitos autorais na era digital. Rio de Janeiro: Editora Record.

Gundlach, G. T., \& Murphy, P. E. (1993). Ethical and legal foundations of relational marketing exchanges. Journal of Marketing, 574), 35-46. http://dx.doi.org/10.2307/1252217.

Gupta, P., Gould, S. J., \& Pola, B. (2004). To pirate or not to pirate: a comparative study of the ethical versus other influences on the consumer's software acquisition-mode decision. Journal of Business Ethics, 55(3), 255-274. http:// dx.doi.org/10.1007/s10551-004-0991-1.

Hair, J.F., Anderson, R. E., Tatham, R. L. \& Black, W. C. (2005). Análise multivariada de dados (5. ed.). Porto Alegre: Bookman.

Harmon, A. (2003). What price music? (Vol. 1). New York: New York Times.

Landim, R., \& Rehder, M. (2010). Metade dos brasileiros compra produto pirata. E País perde US\$ 20 bi. São 
Paulo: 0 Estado de São Paulo. Recuperado em 29 de setembro de 2011, de http://m.estadao.com.br/noticias/ impresso,mobile,552344.htm

Langenderfer, J., \& Cook, D. L. (2001). Copyright policies and issues raised by $\mathrm{A}$ and $\mathrm{M}$ records $\mathrm{v}$. Napster: the shot heard 'round the world' or 'not with a bang but a whimper? Journal of Public Policy \& Marketing, 20(2), 280-288. http://dx.doi.org/10.1509/jppm.20.2.280.17367.

Liang, L. (2004). Guide to open content licenses. Piet Zwart Institute. Recuperado em 30 de agosto de 2009, de http:// media.opencultures.net/open_content_guide/ocl_v1.2.pdf

Marin, D. C. (2011). EUA tiram Brasil de lista de pirataria. São Paulo: 0 Estado de S.Paulo. Recuperado em 29 de setembro de 2011, de http://www.estadao.com.br/ estadaodehoje/20110301/not_imp685948,0.php

Morris, M., \& Ogan, C. (1996). The internet as mass medium. Journal of Communication, 46(1), 39-50. http://dx.doi. org/10.1111/j.1460-2466.1996.tb01460.x.

Mowen, J. C., \& Minor, M. S. (2006). Comportamento do consumidor. São Paulo: Prentice Hall.
Naím, M. (2006). llícito: o ataque da pirataria, da lavagem de dinheiro e do tráfico à economia global. Rio de Janeiro: Jorde Zahar Editor Ltda.

Nettler, G. (1984). Explaining crime. New York: McGraw-Hill. Recuperado em 30 de agosto de 2009, de http://search. ebscohost.com/login.aspx?direct=true $\& \mathrm{db}=\mathrm{sih} \& \mathrm{AN}=\mathrm{SN} 0$ 49225\&site=ehost-live

Ruegger, D., \& King, E. W. (1992). A study of effect of age and gender upon student business ethics. Journal of Business Ethics, 11(3), 179-186. http://dx.doi.org/10.1007/ BF00871965.

Solomon, M. R. (2002). O comportamento do consumidor: comprando, possuindo e sendo (5. ed.). Porto Alegre: Bookman.

União Brasileira de Vídeo. (2009). Pirataria: não seja vítima, entre nessa luta, cartilha anti-pirataria. Recuperado em 8 de setembro de 2009, de http://www.ubv.org.br/pdf/ cartilha.pdf

Weinberg, M. (2007, fevereiro 28). Pirataria: os riscos da cópia. Revista Veja. Recuperado em 1 de junho de 2010, de http:// veja.abril.com.br/280207/p_100.shtml

\begin{abstract}
Brazil is the fourth-largest country where pirated products are highly commercialized. As a result, the film industry, the overall economy and international relations suffer significant damage. Despite the importance of this issue, there are few empirical studies that examine how consumers decide to engage in this piracy. This research investigates whether ethical, legal, economic and behavioral factors are relevant in the consumer decision-making processes of purchasing pirated DVD films. The methodological approach adopted was quantitative, and the data were analyzed using a technical regression binary logistics model. The study was conducted with 205 Brazilian graduate students. The results suggest that economic and legal factors have the greatest influence in consumer decision-making processes. The results also demonstrated that factors such as considering piracy as illegal, perceiving the original DVD price as fair, and having access to information on the consequences of piracy diminish the intent to engage in DVD piracy.
\end{abstract}

Decision making in purchasing pirated DVD films: analysis of an applied logistic regression model

\title{
Keywords
}

Acquisition-mode decision. Consumer behavior. Logistic regression. 
Prieto, V. C. et al.

Tomada de decisão de compra ... aplicação de regressão logística. Production, v. 25, n. 4, p. 926-935, out./dez. 2015

Apêndice A. Questionário e variáveis mensuradas.

\begin{tabular}{|c|c|}
\hline Variáveis & $\begin{array}{l}\text { Questões } 1 \text { a 11: assinale apenas uma alternativa. } \\
\text { Questões } 12 \text { a 20: utilize a escala de } 1=\text { Discordo totalmente a } 5=\text { Concordo totalmente }\end{array}$ \\
\hline \multirow[b]{2}{*}{ Sexo/Renda } & 1) Sexo: $\square$ Feminino $\square$ Masculino \\
\hline & $\begin{array}{l}\text { 2) Renda familiar mensal (valor medido por SM - salário mínimo): } \\
\square \text { Até } 1 \text { SM }(\mathrm{R} \$ 510,00) / \square \text { 1 SM a } 3 \mathrm{SM}(510,01 \text { a } 1.530,00) / \\
\square \text { 3 SM a } 5 \mathrm{SM}(1.530,01 \text { a } 2.550) / \square 5 \mathrm{SM} \text { a } 10 \mathrm{SM}(2.550,01 \text { a } 5.100,00) / \\
\square \text { Acima de } 10 \mathrm{SM}(5.100,00)\end{array}$ \\
\hline \multirow{6}{*}{ Comportamental } & $\begin{array}{l}\text { 3) Qual a frequência com que você assiste filmes? } \\
\square \text { Nunca } \square \text { Raramente } \square \text { Frequentemente } \square \text { Sempre }\end{array}$ \\
\hline & $\begin{array}{l}\text { 4) Qual sua principal fonte para ver filmes? } \\
\square \text { Cinema } \square \text { Alugar DVD } \square \text { TV Download na internet } \square \text { Comprar DVD original } \square \text { Comprar DVD pirata }\end{array}$ \\
\hline & 5) Você já comprou DVD pirata e/ou fez download de filmes? $\square \operatorname{Sim} \square$ Não \\
\hline & $\begin{array}{l}\text { 6) Quantas vezes você comprou DVD pirata e/ou fez download de filmes no último ano? } \square \text { Nenhuma } \square 1 \text { vez } \\
\square \text { De } 2 \text { a } 5 \text { vezes } \square \text { De } 6 \text { a } 10 \text { vezes } \square \text { Acima de } 10 \text { vezes }\end{array}$ \\
\hline & $\begin{array}{l}\text { 7) Você compraria DVD pirata ou faria download de filmes novamente? Se sim, principalmente por quê? } \square \text { É barato } \\
\square \text { É lançado antes do original } \square \text { É mais cômodo } \square \text { Todo mundo faz } \square \text { É de fácil acesso/ } \square \text { É importante para a } \\
\text { difusão cultural/ } \square \text { Não compraria novamente }\end{array}$ \\
\hline & $\begin{array}{l}\text { 8) Qual o motivo principal para você não comprar DVD pirata e/ou fazer downloads de filmes? } \\
\square \text { Medo de ser punido legalmente } \square \text { Acho antiético } \square \text { Seria repreendido pelos outros } \square \text { Tem baixa qualidade } \\
\square \text { Prejudico os profissionais }\end{array}$ \\
\hline \multirow{6}{*}{ Legal } & $\begin{array}{l}\text { 9) } 0 \text { que você acha da comercialização pirata de filmes? } \\
\square \text { Quem comercializa deve ser punido legalmente } \square \text { Não deve acontecer nada com quem comercializa } \\
\square \text { Tudo bem piratear apenas filmes de grandes produtoras }\end{array}$ \\
\hline & $\begin{array}{l}\text { 10) } 0 \text { que você acha sobre quem compra DVD pirata e/ou faz download de filmes? } \\
\square \text { Deve ser punido legalmente } \square \text { Deve ser informado de todas as consequências } \\
\square \text { Não deve acontecer nada } \square \text { Tudo bem para consumo próprio }\end{array}$ \\
\hline & $\begin{array}{l}\text { 11) Você conhece as leis brasileiras sobre a pirataria? } \\
\square \text { Conheço } \square \text { Conheço pouco } \square \text { Não conheço }\end{array}$ \\
\hline & 12) A pirataria de filmes é uma prática ilegal (crime). $\square \square \square \square \square$ \\
\hline & 13) Downloads de filmes é uma forma de pirataria. $\square \square \square \square \square$ \\
\hline & 14) É fácil piratear sem ser descoberto pelas autoridades. $\square \square \square \square \square$ \\
\hline \multirow{2}{*}{ Ética } & 15) Ao fazer um download de filme estou prejudicando alguém. $\square \square \square \square \square$ \\
\hline & 16) DVDs piratas e download de filmes ajudam a levar cultura a quem consome. $\square \square \square \square \square$ \\
\hline \multirow{4}{*}{ Econômica } & $\begin{array}{l}\text { 17) } 0 \text { preço de um DVD original de filmes é: } \\
\square \text { Barato } \square \text { Justo } \square \text { Caro } \square \text { Não sei opinar }\end{array}$ \\
\hline & $\begin{array}{l}\text { 18) } 0 \text { consumo de produtos piratas afeta negativamente o lucro das produtoras e conseqüentemente a produção de } \\
\text { filmes. } \square \square \square \square \square\end{array}$ \\
\hline & 19) A pirataria contribui para o aumento no preço dos DVDs originais de filmes. $\square \square \square \square \square$ \\
\hline & 20) A economia de um país é afetada pela pirataria. $\square \square \square \square \square$ \\
\hline
\end{tabular}

